\title{
Statins are not associated with a decrease in all cause mortality in a high-risk primary prevention setting
}

\section{Bernhard M Kaess, ${ }^{1}$ Ramachandran S Vasan ${ }^{2}$}

10.1136/ebm1125

${ }^{1}$ Framingham Heart Study and Klinik und Poliklinik für Innere Medizin II, University of Regensburg, Regensburg, Germany

${ }^{2}$ Framingham Heart Study and Section of Preventive Medicine and Epidemiology, Boston University School of Medicine, Boston, Massachusetts, USA

\section{Correspondence to:}

\section{Bernhard M Kaess}

73 Mount Wayte Avenue,

Suite 2, Framingham, MA 01702-5803, USA;

kaess@bu.edu

Published Online First

11 January 2011

\author{
Commentary on: Ray KK, Seshasai SR, Erqou S, et al. Statins and all-cause mortality in high-risk \\ primary prevention: a meta-analysis of 11 randomized controlled trials involving 65,229 participants. \\ Arch Intern Med 2010;170:1024-31.
}

\section{Context}

Low-density lipoprotein (LDL) cholesterol (LDL-C) is a risk factor for cardiovascular disease (CVD). Statins (3-hydroxy-3-methylglutaryl-coenzyme A reductase inhibitors) lower LDL-C concentrations by about 30-50\% and have been shown to reduce mortality in patients with prevalent CVD. However, it is not clear whether statin treatment is beneficial in a primary prevention setting, that is in people without prevalent CVD who are at relatively lower risk. The recent results of the JUPITER trial ${ }^{1}$ have fuelled an intense debate whether statins should be given for primary prevention of CVD.

\section{Methods}

The authors performed a literature search in MEDLINE and Cochrane Collaboration databases to identify randomised controlled trials of statin use comprising patients without prevalent CVD at baseline. For trials partly containing CVD patients, the authors obtained tabular data for the individuals without a history of CVD. A meta-analysis was performed using both random effects and fixed effects models. The primary outcome of interest was allcause mortality. Potential publication bias was assessed by the funnel plot and Egger's test.

\section{Findings}

The authors indentified 11 studies that met their inclusion criteria and that provided the required data, two of them containing only patients with diabetes. In total, 65229 patients with an average follow-up of 3.7 years were analysed, resulting in approximately 244000 person-years of observation. Mean age at recruitment varied from 51 to 75 years. The age at time of recruitment was the only baseline correlate of mortality, while LDL-C concentration was not predictive of mortality. Statin therapy was not associated with a significant survival benefit (RR for statin users compared to non-users of: 0.91, 95\% CI 0.83 to 1.01 ; and $0.93,95 \% \mathrm{CI} 0.86$ to 1.00 , in random effects and fixed effects models, respectively). The exclusion of the two trials comprising only patients with diabetes did not substantively change these results. Furthermore, the authors did not find a correlation between mortality reduction and baseline LDL-C concentration or with relative LDL-C reduction in the treatment arm. A relevant publication bias could not be detected.

\section{Commentary}

The authors present a meta-analysis of the effects of statin treatment on all-cause mortality in intermediate to highrisk patients without prevalent CVD. This investigation is by far the largest analysis of statin therapy in a purely primary prevention setting. Although the cohorts varied considerably with respect to the recruitment strategy, mean age and cardiovascular risk profile, the authors observed a consistent null result (for statin benefit) independent of mean baseline LDL concentration and mean LDL-C reduction in the treatment arm and without evidence of relevant heterogeneity across cohorts. A non-significant $8 \%$ risk reduction in a study of this size excludes a clinically relevant survival benefit for statin therapy in the assessed population over the limited observation time.

This study therefore questions the widespread practice of prescribing statins to middle-aged patients with an average cardiovascular risk profile who do not have overt CVD. The cohorts included in the meta-analysis had a mean mortality of $11.4 / 1000$ person-years (in the placebo-arms), and therefore represent an intermediate to high-risk population. The inference can be made that individuals with lower cardiovascular risk are likely to benefit even less from statin therapy.

Nevertheless, there are some questions that this study cannot answer. First, the mean follow-up is only 3.7 years, hence conclusions on potential long-term benefits of statin intake cannot be drawn. Some investigators argue that long-term exposure to higher LDL cholesterol is likely to 
increase lifetime cardiovascular burden and therefore benefits from lowering of LDL cholesterol could be expected on long-term follow-up. Other experts have noted the potential for drug toxicity that may be accumulating over years of statin intake, including risk of developing diabetes. ${ }^{2}$ Longterm studies are warranted to address this issue. Second, allcause mortality is an end point that has a low frequency in a primary prevention setting. Major cardiovascular events and cardiovascular morbidity (and associated impairment in quality of life) may be important outcomes that more closely reflect treatment benefits in a primary prevention population seen in general practice. Third, since the meta-analysis did not have access to individual-level data, subgroup analyses (such as stratified by gender, age, risk profile) could not be performed. This study cannot answer the crucial question if there are select subgroups that may actually benefit from statin therapy in a primary prevention setting.
Taken together, the study is the first to meta-analyse statin therapy in a purely primary prevention setting. Its conclusive null result (for statin benefit on all-cause mortality) raises important questions about the current practice of widespread use of statins for primary prevention of CVD in individuals with average cardiovascular risk.

\section{Competing interests None.}

\section{References}

1. Ridker PM, Danielson E, Fonseca FA, et al. Rosuvastatin to prevent vascular events in men and women with elevated C-reactive protein. N Engl J Med 2008;359:2195-207.

2. Sattar N, Preiss D, Murray HM, et al. Statins and risk of incident diabetes: a collaborative meta-analysis of randomised statin trials. Lancet 2010;375:735-42. 
Statins are not associated with a decrease in all cause mortality in a high-risk primary prevention setting

Bernhard M Kaess and Ramachandran S Vasan

Evid Based Med 2011 16: 8-9 originally published online January 11, 2011

doi: $10.1136 /$ ebm1125

Updated information and services can be found at:

http://ebm.bmj.com/content/16/1/8

These include:

References This article cites 3 articles, 0 of which you can access for free at: http://ebm.bmj.com/content/16/1/8\#BIBL

Email alerting Receive free email alerts when new articles cite this article. Sign up in the service box at the top right corner of the online article.

Topic Articles on similar topics can be found in the following collections

Collections

Epidemiologic studies (1092)

Clinical trials (epidemiology) (1594)

Drugs: cardiovascular system (754)

Diabetes (365)

\section{Notes}

To request permissions go to:

http://group.bmj.com/group/rights-licensing/permissions

To order reprints go to:

http://journals.bmj.com/cgi/reprintform

To subscribe to BMJ go to:

http://group.bmj.com/subscribe/ 